\section{Increased serum interleukin- 17A levels correlate with disease severity and poor prognostic factors in patients with alopecia areata}

\author{
Trang Thi Thuy Le, ${ }^{1,2}$ Thang Tat \\ Nguyen, ${ }^{1}$ Chuyen Thi Hong Nguyen, ${ }^{1}$ \\ Hao Trong Nguyen, ${ }^{1,2}$ Trung The Van ${ }^{1}$ \\ 'Department of Dermatology, Faculty of \\ Medicine, University of Medicine and \\ Pharmacy at Ho Chi Minh City, \\ Vietnam; ${ }^{2} \mathrm{Ho}$ Chi Minh City Hospital of \\ Dermato-Venereology, Viet Nam
}

\begin{abstract}
Alopecia areata (AA) is a tissue-specific autoimmune disease characterized by non-scarring and rapid onset of hair loss. Interleukin (IL)-17A is mainly produced by $\mathrm{T}$ helper 17 (Th17) cells and may play a crucial role in the pathogenesis of various autoimmune diseases including AA. We conducted this research to measure serum level of IL-17A in patients with AA and investigated its relationship with the clinical manifestations in patients with AA. We assessed 36 patients with AA and 20 healthy control subjects. Demographic information and clinical characteristics were determined by physical examination and via the review of medical history. Serum IL-17A was measured by using enzyme-linked immunosorbent assay. Serum IL-17A concentration was significantly higher in patients with AA than in the control group $(\mathrm{P}=0.004)$. The AA patients with severe presentation, personal atopy, nail abnormalities, or active phase had significantly higher serum IL17A levels compared to others without these signs. Increased serum IL-17A levels in patients with AA correlate with severity and indicate an active disease state. These findings suggest that IL-17A may play an important role in determining the pathogenesis of AA and may serve as a valuable clinical biomarker of this disease.
\end{abstract}

\section{Introduction}

Alopecia areata (AA) is considered as an organ-specific autoimmune disease of the hair follicles with a genetic background $;{ }^{1}$ it affects approximately $0.1-0.2 \%$ of the general population and has a lifetime risk of nearly $1.7 \%$. AA affects both genders equally and can occur at any age but is mainly observed in patients less than 30 years old. Hair loss typically presents as asymptomatic, well-demarcated round, or oval-shaped patches in any hair-bearing locations of the body. Such patients may suffer from psychological problems, leading to depression and social isolation.

The exact etiology and pathogenesis of AA are not fully understood; therefore, the disease is difficult to control, and the rate of relapse remains high. In severe cases, such as in the case of alopecia totalis (AT) and alopecia universalis (AU), patients can completely lose their hair of the scalp and all of the body hair, respectively. ${ }^{1} \mathrm{AA}$ is an inflammatory disease of the hair follicles and is mediated by $\mathrm{T}$ lymphocytes. Histological preparations of the scalp of patients with AA show lymphocytic infiltration and cytokine production around anagen hair follicles. AA is also associated with a high frequency of other autoimmune diseases, such as thyroid diseases, vitiligo, systemic lupus erythematosus (SLE), inflammatory bowel disease, psoriasis, and psoriatic arthritis. Several studies in the late 1990s concluded that IL-17 plays a role in the pathogenesis of autoimmunity. ${ }^{2}$ Interleukin$17 \mathrm{~A}$ is the most well-characterized member of the IL-17 cytokine family, and recent studies provided evidence that IL-17A is crucially involved in the pathogenesis of AA and other autoimmune diseases.,3,4 Currently, available treatment for AA has limited effectivity because the pathogenesis of the disease is not yet clearly known; as such, the disease diminishes patients' quality of life. Therefore, this study aimed to measure the serum concentration of IL-17A in patients with AA and investigate the relationship between serum IL-17A and AA clinical characteristics.

\section{Materials and methods}

\section{Study population}

This study was conducted in the Ho Chi Minh City Hospital of DermatologyVenereology, Vietnam between January 2019 and July 2019. A total of 36 patients diagnosed with AA and 20 healthy volunteers. Exclusion criteria were patients with AA treated with either topical or systemic anti-inflammatory or immunosuppressive agents. Other types of alopecia, pregnancy, and lactation or patients with some diseases that known to be associated with increased serum IL-17A level were also excluded. All participants signed informed consent after fully understanding the benefits and risks of this study.

The clinical examination was performed by qualified dermatologists. Age, gen-
Correspondence: Chuyen Thi Hong Nguyen, Department of Dermatology, University of Medicine and Pharmacy at Ho Chi Minh city, Viet Nam.

Tel.: +84.2838566154

E-mail: chuyennguyen@ump.edu.vn

Key words: IL-17A, Alopecia areata, Prognostic factors.

Acknowledgments: The authors would thank all the patients who agreed to take part in the study.

Contributions: Conceptualization, CTHN Data curation, TTTL, TTN, and CTHN; Investigation, TTTL, TTN, and CTHN; Methodology, TTTL, TTN, CTHN, HTN and TTV; Project administration, TTTL and CTHN; Supervision, CTHN and TTV; Writing-original draft, TTTL, TTN and CTHN; Writing-review and editing, TTTL, TTN, CTHN, HTN and TTV.

Conflict of interest: The authors declare no potential conflict of interest.

Funding: None.

Ethical approval: Ethical approval was sought and granted by the Board of Ethics in Biomedical Research from the University of Medicine and Pharmacy at Ho Chi Minh City in Vietnam in line with the Helsinki declarations for ethics and medical research. The study was issued a code 483/UMP-BOARD.

Please cite this article as: Le TTT, Nguyen TT, Nguyen $\mathrm{CTH}$, et al. Increased serum interleukin-17A levels correlate with disease severity and poor prognostic factors in patients with alopecia areata. Dermatol Rep 2022;14:9398.

Received for publication: 10 October 2021. Accepted for publication: 12 October 2021.

This work is licensed under a Creative Commons Attribution-NonCommercial 4.0 International License (CC BY-NC 4.0).

Copyright: the Author(s), 2021

Licensee PAGEPress, Italy

Dermatology Reports 2022; 14:9398

doi:10.4081/dr.2021.9398

Publisher's note: All claims expressed in this article are solely those of the authors and do not necessarily represent those of their affiliated organizations, or those of the publisher, the editors and the reviewers. Any product that may be evaluated in this article or claim that may be made by its manufacturer is not guaranteed or endorsed by the publisher.

ders, general health of patients, onset and course of disease were documented. Nail abnormalities were recorded. The severity 
of hair loss in the scalp was determined using the Severity of Alopecia Tool (SALT) score. Briefly, total affected area and diameter of the largest hair loss patches were evaluated to assess the clinical scale of AA severity as follows: mild (three or fewer patches of alopecia with the widest diameter of $<3 \mathrm{~cm}$ or disease limited to eyelashes and eyebrows); moderate (more than three patches of alopecia or a patch with the widest diameter $>3 \mathrm{~cm}$ without AT or AU); AT, AU, and ophiasis, which are considered severe AA.5,6

\section{Blood sample preparation}

Up to $3 \mathrm{~mL}$ of peripheral blood samples with EDTA were obtained from patients with AA and healthy control subjects, then stored in serum separator test tubes. The blood samples were addressed to measure serum IL-17A by using enzyme-linked immunosorbent assay (ELISA) via a Human IL-17A ELISA kit (ANOGEN, Ontario, Canada) according to instruction of the manufacterer. Anti-nuclear antibodies were also investigated in all cases.

\section{Statistical analyses}

STATA version 13 were applied in this study. Chi-square test, Student's $t$-test and ANOVA test, Mann-Whitney and KruskalWallis tests, Spearman correlation test were used when applicable. A P value of $<0.05$ was considered significant in all statistical tests.

\section{Results}

Of the 36 patients with AA, there were $18(50 \%)$ male and $18(50 \%)$ female patients, with a mean \pm standard deviation (SD) age of $29.11 \pm 14.00$ years (range 5-60 years). There were $52.8 \%$ of patients with the age younger than 30 years, and disease duration was less than 6 months in 23/36 patients. Of the 20 healthy volunteers, 9 $(45 \%)$ were males and $11(55 \%)$ were females with ages ranging from 26 years to 43 years and with a mean \pm SD age of $34.75 \pm 5.50$ years (range $26-43$ years). The demographic and clinical manifestations of patients with AA are summarized in Table 1. The single patch pattern was dominant with $17 / 36$ cases $(47.2 \%)$, and erythema within the patch was observed in $58.3 \%$ of cases. The majority of patients presented moderate severity, and nail involvement was detected among $38.9 \%$ of the patients.

\section{Serum concentration of IL-17A increased in the group of patients with AA}

Serum IL-17A in patients with AA ranged from $0.6-346.33 \mathrm{pg} / \mathrm{mL}$, and median (interquartile range) was 9.21 (3.62-49.70) $\mathrm{pg} / \mathrm{mL}$. In the control group, serum IL-17A ranged from $1.38 \mathrm{pg} / \mathrm{mL}$ to $16.41 \mathrm{pg} / \mathrm{mL}$ and median (interquartile range) was 2.8

(1.8-5.76) $\mathrm{pg} / \mathrm{mL}$. The serum IL-17A level was significantly higher in patients with AA compared with healthy subjects $(\mathrm{P}=0.004$, Mann-Whitney U-test, Figure 1).

Table 1. Demographic and clinical characteristics of patients with alopecia areata.

\begin{tabular}{|c|c|}
\hline Characteristics & Patients with $\mathrm{AA}(\mathrm{N}=36)$ \\
\hline $\begin{array}{l}\text { Gender }(\mathrm{n}, \%) \\
\quad \text { Males } \\
\text { Females }\end{array}$ & $\begin{array}{l}18(50) \\
18(50)\end{array}$ \\
\hline $\begin{array}{l}\text { Ages } \\
\text { Range } \\
\text { Mean } \pm \text { SD }\end{array}$ & $\begin{array}{c}5-60 \\
30.5 \pm 13.7\end{array}$ \\
\hline $\begin{array}{l}\text { Age }(\mathrm{n}, \%) \\
\quad<=30 \\
\quad>30\end{array}$ & $\begin{array}{l}19(52.8) \\
17(47.2)\end{array}$ \\
\hline $\begin{array}{l}\text { Age at disease onset (n, \%) } \\
\text { Early onset }(<=35 \text { age) } \\
\text { Late onset }(>35 \text { age) }\end{array}$ & $\begin{array}{l}24(66.7) \\
12(33.3)\end{array}$ \\
\hline $\begin{array}{l}\text { Duration of disease (month) } \\
\quad \text { Mean (SEM) } \\
\quad \leq 6 \text { months } \\
>6 \text { months }\end{array}$ & $\begin{array}{l}7.1(1.99) \\
23(63.9) \\
13(36.1)\end{array}$ \\
\hline Atopy $(\mathrm{n}, \%)$ & $14(38.9)$ \\
\hline $\begin{array}{l}\text { Family history }(\mathrm{n}, \%) \\
\text { Yes } \\
\text { No }\end{array}$ & $\begin{array}{c}3(8.3) \\
33(91.7)\end{array}$ \\
\hline $\begin{array}{l}\text { Pattern of hair loss (n, \%) } \\
\text { Single patch } \\
\text { Multiple patches } \\
\text { Ophiasis } \\
\text { Diffuse AA }\end{array}$ & $\begin{array}{l}17(47.2) \\
11(30.6) \\
1(2.8) \\
7(19.4)\end{array}$ \\
\hline $\begin{array}{l}\text { Characteristics of the patches (n, \% } \\
\text { Exclamation mark hair positive } \\
\text { White hair } \\
\text { Pull hair test positive }\end{array}$ & $\begin{array}{c}32(88.9) \\
24(66.7) \\
9(25)\end{array}$ \\
\hline $\begin{array}{l}\text { Erythema within patch } \\
\text { Pain } \\
\text { Itch }\end{array}$ & $\begin{array}{c}21(58.3) \\
3(8.3)\end{array}$ \\
\hline
\end{tabular}

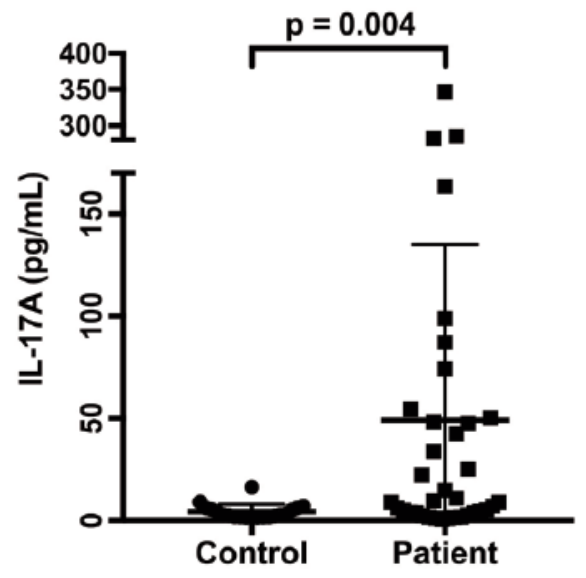

Figure 1. Serum IL-17A levels in patients with AA and the control group. The IL-17A levels were significantly higher in patients with $A A$ than in normal subjects. $P$ values were calculated with the unpaired Mann-Whitney test, where $p<0.05$ was significant. Data are shown as the median (range), for which range is the $25^{\text {th }}$ to $75^{\text {th }}$ percentile. All values represent individuals. AA, alopecia areata. 


\section{Increased serum levels of IL-17A in} patients with AA with severe disease and poor prognostic factors

Twelve of the patients $(36.4 \%)$ were diagnosed with atopic diseases, including atopic dermatitis, allergic rhinitis, and asthma. The difference in serum IL-17A concentration between patients with AA and those without associated atopy was significant $(\mathrm{P}=0.004$, Mann-Whitney U-test). Nail abnormalities, including pitting, trachyonychia, longitudinal ridging, Beau's lines, and onycholysis, were noted in 14/36 (38.9\%) of patients. The serum IL-17A levels of patients with AA with nail involvement were significantly higher compared with those of patients with AA without nail involvement ( $\mathrm{P}=0.012$, Mann-Whitney Utest) (Table 2). However, no other statistically significant differences were found between the serum IL-17A levels and any of the demographics or clinical manifestations, including gender, current age, age at onset, duration of disease, family history, pattern of AA, exclamation mark hair, pain, itch, and SALT classification, of patients with AA (data not shown).

The hallmarks of active disease, including positive hair pull test, ${ }^{1,7}$ and the presence of erythema within the patch, were found in $25 \%$ and $58.3 \%$ of cases, respectively. Table 3 shows that the serum IL-17A levels in these patients were significantly higher than those in patients without these positive signs $(\mathrm{P}=0.028$ and $\mathrm{P}=0.004$, Mann-Whitney U-test, respectively). Two representative cases of AA with different patch characteristics are shown in Figure 2. A female patient (patient ID 18) with a single lesion lasting for 1 month, with mild edema and erythema within the patch concurrent with itch, exhibited a significant increase in serum IL-17A levels at 98.87 $\mathrm{pg} / \mathrm{mL}$. Nail pitting and atopic dermatitis were also reported (Figure 2a). In contrast, another female patient (patient ID 32) with a 7-month history showed a single patch of AA without other significant symptoms. Her serum IL-17A levels were low at 3.6 $\mathrm{pg} / \mathrm{mL}$ (Figure $2 \mathrm{~b}$ ).

Based on clinical severity of the disease, the number of patients (percentage) in mild, moderate, and severe groups was 9 $(25 \%), 5(13.9 \%)$, and $1(2.8 \%)$, respectively, and $1(2.8 \%)$ patient had ophisasis. Table 3 shows that the difference in median serum levels of IL-17A was significant among different degrees of clinical severity ( $\mathrm{P}=0.009$, Kruskall-Wallis test).

\section{Discussion}

Alopecia areata is a non-scarring type
Table 2. Correlation between serum concentration of IL-17A and demographic features in alopecia areata patients $(\mathrm{N}=36)$.

\begin{tabular}{|c|c|c|}
\hline Characteristics & $\begin{array}{l}\text { IL-17A (pg/mL) } \\
\text { Median (interquartile range) }\end{array}$ & P-value \\
\hline $\begin{array}{l}\text { Gender } \\
\text { Female } \\
\text { Male }\end{array}$ & $\begin{array}{c}6.87(3.30-59.46) \\
10.23(4.66-45.32)\end{array}$ & 0.88 \\
\hline $\begin{array}{l}\text { Current age } \\
\quad<=30 \\
>30\end{array}$ & $\begin{array}{l}10.86(2.73-54.37) \\
8.81(4.16-48.85)\end{array}$ & 0.75 \\
\hline $\begin{array}{c}\text { Age at disease onset }(\mathrm{n}, \%) \\
\text { Early onset }(<=35 \text { age }) \\
\text { Late onset }(>35 \text { age })\end{array}$ & $\begin{array}{c}7.87(2.95-46.72) \\
15.92(4.22-86.70)\end{array}$ & 0.66 \\
\hline $\begin{array}{l}\text { Duration of disease } \\
\text { Acute ( } \leq 6 \text { months) } \\
\text { Chronic (>6 months) }\end{array}$ & $\begin{array}{c}6.94(2.73-48.19) \\
14.77(4.45-108.95)\end{array}$ & 0.08 \\
\hline $\begin{array}{l}\text { Atopy } \\
\text { Yes } \\
\text { No }\end{array}$ & $\begin{array}{c}50.94(7.92-147.36) \\
5.12(1.90-30.87)\end{array}$ & 0.004 \\
\hline $\begin{array}{l}\text { Family history } \\
\text { Yes } \\
\text { No }\end{array}$ & $\begin{array}{c}6.94(6.55-40.62) \\
9.6(3.17-49.20)\end{array}$ & 0.68 \\
\hline
\end{tabular}

Values are median (range) with range of $25^{\text {th }}$ to $75^{\text {th }}$ percentiles and statistically significant at $\mathrm{P}<0.05$ as indicated by Mann-Whitney U-test and Kruskall-Wallis test.

Table 3. Correlation between serum concentration of IL-17A and clinical manifestations in patients with alopecia areata $(\mathrm{N}=36)$.

\begin{tabular}{|c|c|c|}
\hline \multicolumn{2}{|c|}{$\begin{array}{cc}\text { Characteristics } & \text { IL-17A (pg/mL) } \\
& \text { Median (Interquartile range) }\end{array}$} & P-value \\
\hline $\begin{array}{l}\text { Pattern of AA } \\
\text { Single patch } \\
\text { Multiple patches } \\
\text { Ophiasis, diffuse AA, alopecia totalis }\end{array}$ & $\begin{array}{c}10.86(3.01-63.34) \\
6.94(3.60-38.03) \\
28.50(4.13-193.92)\end{array}$ & 0.54 \\
\hline Charact & istics of the patchs $(n, \%)$ & \\
\hline $\begin{array}{l}\text { Exclamation mark hair } \\
\text { Negative } \\
\text { Positive }\end{array}$ & $\begin{array}{l}21.68(3.62-44.06) \\
8.80(3.62-53.33)\end{array}$ & 0.53 \\
\hline $\begin{array}{l}\text { White hair } \\
\text { Negative } \\
\text { Positive }\end{array}$ & $\begin{array}{c}4.31(1.97-22.43) \\
16.55(4.67-69.32)\end{array}$ & 0.043 \\
\hline $\begin{array}{l}\text { Hair pull test } \\
\text { Negative } \\
\text { Positive }\end{array}$ & $\begin{array}{c}5.3(2.42-14.77) \\
74.3(40.63-131.20)\end{array}$ & 0.028 \\
\hline $\begin{array}{l}\text { Erythema within patch } \\
\text { Negative } \\
\text { Positive }\end{array}$ & $\begin{array}{c}3.69(1.43-6.94) \\
47.5(9.84-93.05)\end{array}$ & 0.004 \\
\hline $\begin{array}{l}\text { Pain } \\
\text { No } \\
\text { Yes }\end{array}$ & $\begin{array}{c}8.8(3.17-52.29) \\
22.24(16.55-34.87)\end{array}$ & 0.512 \\
\hline $\begin{array}{l}\text { Itch } \\
\text { No } \\
\text { Yes }\end{array}$ & $\begin{array}{l}5.73(1.70-51.24) \\
28.00(7.84-60.86)\end{array}$ & 0.53 \\
\hline $\begin{array}{l}\text { Nail involvement } \\
\text { No } \\
\text { Yes }\end{array}$ & $\begin{array}{c}6.55(1.70-25.12) \\
47.85(5.09-115.03)\end{array}$ & 0.012 \\
\hline $\begin{array}{l}\text { Severity } \\
\text { Mild } \\
\text { Moderate } \\
\text { Severe } \\
\end{array}$ & $\begin{array}{c}2.73(1.53-9.62) \\
22.24(5.55-64.34) \\
48.19(7.05-224.31) \\
\end{array}$ & 0.009 \\
\hline $\begin{array}{l}\text { SALT classification } \\
\text { S1 } \\
\text { S2 } \\
\text { S3-4 } \\
\end{array}$ & $\begin{array}{c}7.88(2.95-49.53) \\
42.30(5.10-105.86) \\
8.80(7.05-146.95) \\
\end{array}$ & 0.56 \\
\hline
\end{tabular}

Values are median (range) with range of 25th to 75th percentiles and statistically significant at $\mathrm{P}<0.05$ as indicated by Mann-Whitney U-test, Kruskall-Wallis test, and ANOVA. 
of hair loss in humans with unknown pathogenesis and unpredictable course. Given the nature of its autoimmune origin, $\mathrm{AA}$ is a chronic and highly recurrent disease. However, evidence suggests that an autoimmune $\mathrm{T}$ cell-mediated process and the breakdown of immune privilege of hair follicles may cause hair loss in AA. ${ }^{8,9}$

Infiltration of $\mathrm{CD} 4+\mathrm{T}$ cell around the hair follicle and of CD8+ T cell within the hair follicle is observed. T helper 17 cells are a distinct subset of Th cells and have recently gained attention due to their association with various inflammatory and autoimmune diseases. ${ }^{10}$ Several studies have shown high levels of IL-17A in chronic immune diseases, such as psoriasis, rheumatoid arthritis, SLE, and multiple sclerosis. ${ }^{11,12}$ In the present study, we also found a significantly higher serum level of IL-17A in patients with AA compared with that in control subjects, and this result is consistent with other previous reports. ${ }^{3,13,14}$

A severe disease that affects a large surface area, AT/AU pattern, long disease duration of more than one-year, early onset, and associated co-morbidities have a negative effect on AA prognosis.1,15,16 Given that AA is an autoimmune disease, an association exists between AA and other conditions. ${ }^{17-23}$ Such additional co-morbidities, such as atopic and autoimmune diseases, have a disease-modifying effect and must be included in the classification of AA and treatment plan. ${ }^{17}$ An atopy background shows a strong $\mathrm{T}$ helper 17 (Th17) polarization, and Asian patients with $\mathrm{AD}$ had significantly higher induction of Th17 cytokines in both non-lesional skin and lesional skin. ${ }^{24}$ Furthermore, prominent Th17 activation has been observed in blood and acute $\mathrm{AD}$ skin lesions. ${ }^{25}$ Therefore, patients with AA who exhibit atopy had significantly higher serum level of IL-17A in the present study and is consistent with previous reports.

Previous reports indicated that nail involvement among patients with AA was between $2 \%$ and $44 \%$ and also observed more frequently in severe cases. ${ }^{26-28}$ An active patch of AA shows exclamation point hairs and skin erythema. ${ }^{9}$ In our study, serum IL-17A levels were significantly increased in patients with AA with active lesions, nail involvement, and high severity. Recently, many studies have contributed to a better understanding of the pathogenesis of AA by elucidating the central role of the Th17 pathway in disease initiation and progression. Th17 cells produce IL-17 and induce chemokines that recruit other effector cell populations, thereby promoting the attack on hair follicles. ${ }^{10,29,30} \mathrm{We}$ observed that in $21 / 36$ of patients $(58.3 \%)$ with erythema within hair-loss patches, the serum IL-17A levels were significantly increased in comparison with others without such signs (Figure 2). In a recent study, significant numbers of IL-17-producing cells were detected in the lesional skin in all types of AA. Thus, IL-17-producing cells may enhance local inflammation in the lesional skin among patients with AA. ${ }^{31}$ This finding suggests the crucial role of IL$17 \mathrm{~A}$ as a marker of disease activity and its possible major role in initiating and amplifying the inflammatory progression of the disease..$^{32}$ Our results are in line with other reports that IL-17A is one of the most important proinflammatory cytokines that may facilitate selective damage to hair follicles in the active phase of AA. Recently, a trial of therapeutic approaches targeting IL$17 \mathrm{~A}$ in patients with AA via secukinumab have showed the lack of treatment response among most of the treated patients; however, the low statistical power of this study suggests that future studies involving a large population may be needed to corroborate these findings. ${ }^{33}$ Given that IL-17A was highly elevated in patients with active lesions in the present study, the Il-17A inhibitor may only be effective for the acute phase of AA and possibly not an ideal treatment for those with a long-lasting and recalcitrant condition. We should point out that there is a limitation in our present study because we substitute circulating IL-17 level instead of its expression within the affected tissue. Further studies including a large number of patients will be required in order to validate the possible contributions and underlying mechanism of different immunologic pathways in AA pathogenesis. ${ }^{34}$

\section{Conclusions}

A significant increase in serum IL-17A levels was related to the presence of active lesions, nail involvement, and disease severity. Our findings indicate that serum IL-17A may serve as a potential biomarker and prognostic indicator for severe and progressive AA. Further studies may require to explore the its role in the AA pathogenesis.
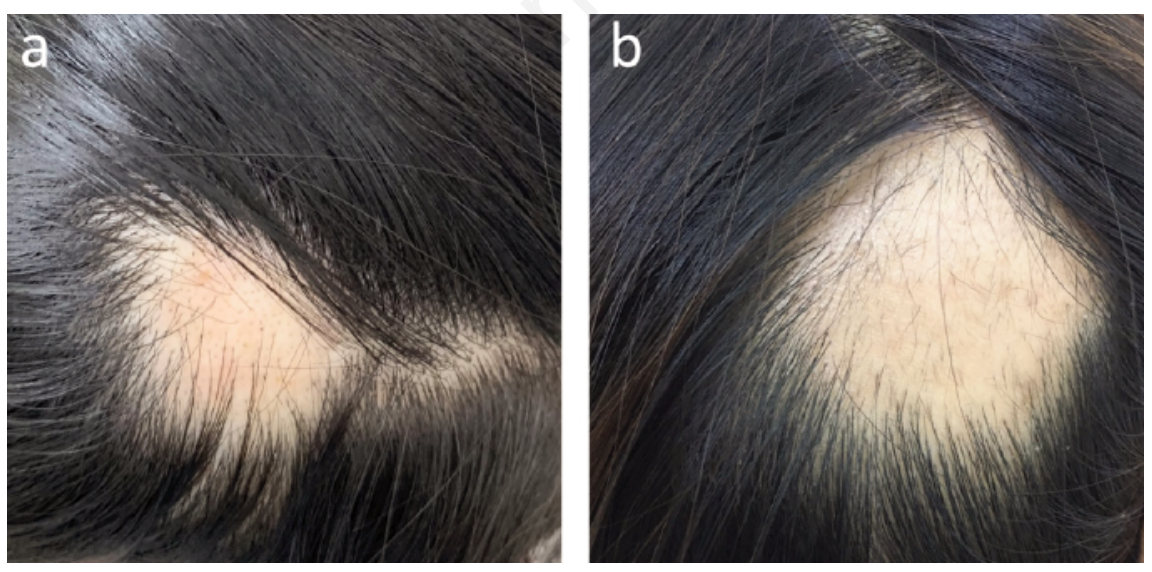

\section{References}

1. Trueb RM, Dias M. Alopecia Areata: a Comprehensive Review of Pathogenesis and Management. Clin Rev Allergy Immunol 2018;54:68-87.

2. Lew BL, Cho HR, Haw $S$, et al. Association between IL17A/IL17RA Gene Polymorphisms and Susceptibility to Alopecia Areata in the Korean Population. Ann Dermatol 2012;24:61-5.

3. Atwa MA, Youssef N, Bayoumy NM. T-helper 17 cytokines (interleukins 17, 21,22 , and 6 , and tumor necrosis factoralpha) in patients with alopecia areata: association with clinical type and severity. Int J Dermatol 2016;55:666-72.

Figure 2. Two representative cases with different AA patch characteristics. a) A female patient with a single lesion lasting for 1 month had a significantly increased serum IL17A level at $98.87 \mathrm{pg} / \mathrm{mL}$. Mild edema and erythema were found and concurrent with itch. Nail involvement and atopic dermatitis were also noted in this patient. b) Another female patient with a history of 7 months of AA showed a single patch of AA. The exclamation mark hairs were found within the patch, but no other symptoms were described. The patient's serum IL-17A level of $3.6 \mathrm{pg} / \mathrm{mL}$ was low.

4. El-Morsy EH, Eid AA, Ghoneim H, AlTameemi KA. Serum level of interleukin-17A in patients with alopecia areata and its relationship to age. Int J Dermatol 2016;55:869-74. 
5. Kavak A, Baykal C, Ozarmagan G, Akar U. HLA in alopecia areata. Int J Dermatol 2000;39:589-92.

6. You HR, Kim SJ. Factors Associated with Severity of Alopecia Areata. Ann Dermatol 2017;29:565-70.

7. Seetharam KA. Alopecia areata: an update. Indian J Dermatol Venereol Leprol 2013;79:563-75.

8. Dainichi T, Kabashima K. Alopecia areata: What's new in epidemiology, pathogenesis, diagnosis, and therapeutic options? J Dermatol Sci 2017;86:312.

9. Pratt $\mathrm{CH}$, King LE Jr., Messenger AG, et al. Alopecia areata. Nat Rev Dis Primers 2017;3:17011.

10. Tembhre MK, Sharma VK. T-helper and regulatory $\mathrm{T}$-cell cytokines in the peripheral blood of patients with active alopecia areata. Br J Dermatol 2013; 169:543-8.

11. Ghilardi N, Ouyang W. Targeting the development and effector functions of TH17 cells. Semin Immunol 2007; 19:383-93.

12. Yu JJ, Gaffen SL. Interleukin-17: a novel inflammatory cytokine that bridges innate and adaptive immunity. Front Biosci 2008;13:170-7.

13. Li SF, Zhang XT, Qi SL, et al. Allergy to dust mites may contribute to early onset and severity of alopecia areata. Clin Exp Dermatol 2015;40:171-6.

14. Bain KA, McDonald E, Moffat F, et al. Alopecia areata is characterized by dysregulation in systemic type 17 and type 2 cytokines, which may contribute to disease-associated psychological morbidity. Br J Dermatol 2020;182:130-7.

15. Madani S, Shapiro J. Alopecia areata update. J Am Acad Dermatol 2000;42:549-70.

16. Alkhalifah A, Alsantali A, Wang E, et al. Alopecia areata update: part I. Clinical picture, histopathology, and pathogenesis. J Am Acad Dermatol 2010;62:177-90.

17. Ikeda T. A new classification of alopecia areata. Dermatologica 1965;131:421-45.

18. Cunliffe WJ, Hall R, Newell DJ, Stevenson CJ. Vitiligo, thyroid disease and autoimmunity. Br J Dermatol 1968; 80:135-9.

19. Cunliffe WJ, Hall R, Stevenson CJ, Weightman D. Alopecia areata, thyroid disease and autoimmunity. $\mathrm{Br} \mathrm{J}$ Dermatol 1969;81:877-81.

20. Seyrafi H, Akhiani M, Abbasi H, et al. Evaluation of the profile of alopecia areata and the prevalence of thyroid function test abnormalities and serum autoantibodies in Iranian patients. BMC Dermatol 2005;5:11.

21. Krishnaram AS, Saigal A, Adityan B. Alopecia areata - Vitiligo overlap syndrome: an emerging clinical variant. Indian J Dermatol Venereol Leprol 2013;79:535-7.

22. Walker A, Mesinkovska NA, Boncher J, et al. Colocalization of vitiligo and alopecia areata presenting as poliosis. J Cutan Pathol 2015;42:150-4.

23. Xin C, Sun X, Lu L, et al. Increased Incidence of Thyroid Disease in Patients with Alopecia Areata: A Systematic Review and Meta-Analysis. Dermatology 2019:1-4.

24. Noda S, Suarez-Farinas M, Ungar B, et al. The Asian atopic dermatitis phenotype combines features of atopic dermatitis and psoriasis with increased TH17 polarization. J Allergy Clin Immunol 2015;136:1254-64.

25. Koga C, Kabashima K, Shiraishi N, et al. Possible pathogenic role of Th17 cells for atopic dermatitis. J Invest
Dermatol 2008;128:2625-30.

26. Tosti A, Morelli R, Bardazzi F, Peluso AM. Prevalence of nail abnormalities in children with alopecia areata. Pediatr Dermatol 1994;11:112-5.

27. Sharma VK, Dawn G, Muralidhar S, Kumar B. Nail changes in 1000 Indian patients with alopecia areata. J Eur Acad Dermatol Venereol 1998;10:189-91.

28. Kasumagic-Halilovic E, Prohic A. Nail changes in alopecia areata: frequency and clinical presentation. J Eur Acad Dermatol Venereol 2009;23:240-1.

29. Teraki Y, Imanishi K, Shiohara $T$. Cytokines in alopecia areata: contrasting cytokine profiles in localized form and extensive form (alopecia universalis). Acta Derm Venereol 1996;76: 421-3.

30. Bettelli E, Carrier Y, Gao W, et al. Reciprocal developmental pathways for the generation of pathogenic effector TH17 and regulatory T cells. Nature 2006;441:235-8.

31. Tojo G, Fujimura T, Kawano M, et al. Comparison of interleukin-17- producing cells in different clinical types of alopecia areata. Dermatology 2013;227:78-82.

32. Tabarkiewicz J, Pogoda K, Karczmarczyk A, et al. The Role of IL17 and Th17 Lymphocytes in Autoimmune Diseases. Arch Immunol Ther Exp (Warsz) 2015;63:435-49.

33. Guttman-Yassky E, Nia JK, Hashim PW, et al. Efficacy and safety of secukinumab treatment in adults with extensive alopecia areata. Arch Dermatol Res 2018;310:607-14.

34. Gautam RK, Singh Y, Gupta A, et al. The profile of cytokines (IL-2, IFNgamma, IL-4, IL-10, IL-17A, and IL23) in active alopecia areata. J Cosmet Dermatol 2020;19:234-40. 